\title{
Cultural Differences in Leadership Styles of Pharmacist Preceptors
}

\author{
Nile M. Khanfar ${ }^{1}$, Catherine A Harrington ${ }^{2}$, Fadi M. Alkhateeb ${ }^{3}$ \& Belal A. Kaifi ${ }^{4}$ \\ ${ }^{1}$ Ph.D, MBA, Associate Professor, Socio-behavioral and Administrative Pharmacy, Nova Southeastern University, \\ USA \\ ${ }^{2}$ PharmD, PhD, Associate Professor, Socio-behavioral and Administrative Pharmacy, Nova Southeastern University, \\ USA \\ ${ }^{3}$ BSPharm, MBA, Ph.D, Associate Professor \& Director of EMBA in Pharmaceutical \& Healthcare Management \\ Program, University of Charleston School of Pharmacy, USA \\ 4 MBA, PhD, Associate Professor of Business Administration, College of Business Administration, Trident \\ University International, USA \\ Correspondence: Nile M. Khanfar, Ph.D, MBA, Associate Professor, Socio-behavioral and Administrative Pharmacy, \\ Nova Southeastern University, USA. E-mail: khanfar@nova.edu
}

Received: October 18, 2012

Accepted: November 14, 2012

Online Published: January 7, 2013

doi:10.5430/bmr.v2n1p1

URL: http://dx.doi.org/10.5430/bmr.v2n1p1

\begin{abstract}
Pharmacists often work in teams and care for patients from a variety of cultures. Pharmacists may have a formal or informal leadership role within the work team. This study allowed a group of pharmacists with responsibility as preceptors for students to assess their own leadership style. This knowledge could be used to increase the cultural competence of pharmacists and improve their leadership effectiveness. A total of 131 pharmacy preceptor responses were received of which about half were from females and half from males. The results of this study found that mean leadership style did vary significantly based upon several attributes. We found that the majority of pharmacist preceptors surveyed have a selling style of leadership, similar to two previous surveys of pharmacy leadership styles. Multilingual preceptors, especially those in management roles, will tend to have higher task expectations than most of the staff and students they interact with on a daily basis. Implications and limitations are also discussed.
\end{abstract}

Keywords: Pharmacists, Leadership style, Culture, Preceptors

\section{Introduction}

The United States has a diverse population and continues to diversify, particularly with higher numbers of persons from a variety of Hispanic and Asian cultures (US Census 2009, please see Table 1). Culture is important because it influences what a person values and their behavior is driven by those values (Pohlman 2000). Conflict in the workplace may occur when workers from different cultures assign dissimilar levels of importance to the same value. For example, Hispanic cultures tend to value relationships very highly and consider task achievement secondary to maintaining personal connections. People of German decent tend to have a more task orientation and consider relationships as secondary (Jones 2009). On the contrary, people from Afghanistan tend to focus more on relationships when compared to tasks (Mujtaba \& Kaifi, 2010).

Pharmacists often work in teams and care for patients from a variety of cultures. Pharmacists may have a formal or informal leadership role within the work team. An effective leader reflects on their own cultural influences and examines how differences can lead to misunderstandings with persons from different backgrounds. There is a paucity of literature on leadership styles of pharmacists and the impact culture has on their leadership styles. Only two published reports that examined the leadership styles of pharmacists could be located. Both were reports on national surveys conducted several years ago. Those reports showed that American pharmacists (mostly white males at that time) exhibited a predominantly selling (high relationship and high task) style of leadership (Parret 1985, Ibrahim 1997).

In one of those studies, leadership styles of hospital pharmacy directors were examined using a mailed survey to a nationally representative sample of 570 randomly selected participants (Parrett 1985). The survey response rate was $69 \%$. The dominant leadership style was selling (high task and high relationship) mode at $68 \%$. Participating style (low task and high relationship) was next at $18 \%$. The Telling style (high task and low relationship) was dominant in 
only $1 \%$ of directors. A portion (13\%) had no dominant style. None of the respondents had a delegator style of low task and low relationship. Cultural attributes measured included age, gender, years as a pharmacy director, and geographic region. No significant differences in style were found among these factors.

In the second study, Ibrahim and Wertheimer (1997) evaluated the leadership styles of community pharmacists and executive officers of pharmacy associations. A national survey of 1,001 participants was conducted with the LEAD-Self instrument (Hersey 1977). The survey response rate was $40 \%$. The respondents included 177 community pharmacists and 223 association pharmacist surveys. The dominant leadership style among community pharmacists was selling (67\%), with other styles at lower rates (participating 15\% and telling $4 \%$ ). Nearly $14 \%$ had no dominant style and no community pharmacists were dominantly delegators. Effectiveness of their leadership styles was in the moderate to low levels indicating the need for development of leadership programs for pharmacists. No cultural attribute data was collected in that study.

Much has changed in pharmacy since these two surveys were conducted. The need to sell to people is not emphasized in pharmacy education. Pharmacists are primarily employees of large corporations and are no longer entrepreneurs. Pharmacists are being trained to explain medications to their patients and participate in their care more directly. Also, many more women and minorities have entered the pharmacy workforce. The backgrounds of practicing pharmacists, like most other health professionals, are less varied in race and ethnicity than the United States (U.S.) population as a whole (See Table 1). However, Florida is more diverse than the U.S. Thus, an opportunity exists to update our knowledge of pharmacist leadership styles and to gather information from a culturally diverse population.

Table 1. Racial demographics (\%) of US Population, US Pharmacists, and Florida

\begin{tabular}{ccccc}
\hline Race/ethnicity & US & US projected \\
$2008^{\mathrm{a}}$ & $600^{\mathrm{a}}$ & $\begin{array}{c}\text { US Pharmacists } \\
2009^{\mathrm{b}}\end{array}$ & $\begin{array}{c}\text { Florida } \\
2008^{\mathrm{a}}\end{array}$ \\
\hline White & 66 & 45 & 86 & 59 \\
Hispanic & 15 & 30 & 3 & 21 \\
Black & 13 & 14 & 2 & 16 \\
Asian & 4 & 9 & 8 & 2 \\
Mixed/Unknown & 2 & 2 & 1 & 2 \\
\hline
\end{tabular}

a. US Census 2008 b. 2009 National Pharmacist Workforce Survey

The purpose of our study is two-fold, first to conduct a study of relationships between culture and leadership style in a more diverse population of pharmacists and secondly, to provide a self assessment tool and leadership training to pharmacist preceptors affiliated with Nova Southeastern University (NSU). Our hypothesis was that leadership style (task versus relationship orientation) varies by culture as defined by several different characteristics of a society. These include: 1) Race and ethnicity 2) Gender 3) Generation 4) First language spoken 5) Country of origin and 6) Religious preference.

Information from this study will allow these pharmacists to assess their own leadership style. This knowledge could be used to increase the cultural competence of pharmacists and improve their leadership effectiveness. By self-assessing leadership style and comparing it to leadership styles of other cultures, pharmacist preceptors will be more aware of how they value relationships and tasks and how that might affect their behavior towards other people. Reducing ethnocentrism (belief in the superiority of one's own ethnic group) is critical to being an effective practitioner. It is very difficult to influence the behavior of a patient or a student who does not trust your judgment. The study is unique in reporting on leadership styles of minority and women pharmacists since previous studies were conducted in largely white, male populations. This study may also have some applicability to other health professions that must respond to cultural change.

\section{Literature Review}

\subsection{Leadership}

Leaders believe in change, energize organizations to innovate, recognize the need for synergy, and emphasize the importance of collaboration. Many organizations have even created in-house programs to help cultivate core leadership skills in their employees (Schwartz, Jones, \& McCarthy, 2010, p. 29). Organizations seek leaders who can influence others to complete tasks, build genuine relationships, and also follow the mission of the organization (Kaifi, 2013). For leaders, it becomes imperative to know their own strengths and to make sure the right people are on their 
team so the best decisions are made (Vroom 1973; Rath \& Conchie, 2009). Leaders have different styles depending on the situation at hand; some focus more on being task-oriented while others focus on being more relationship-oriented. Situational leadership was originally developed by Paul Hersey and Kenneth Blanchard (1969). As the name implies, situational leadership requires adapting to situations that arise because the situational contingencies dictate your style for that moment (Lumsden, Lumsden, \& Wiethoff, 2010, p. 258). Situational leadership is composed of both a directive and supportive dimension, and each has to be applied appropriately in a given situation (Northouse, 2007, p. 87). The directive dimension is similar to "task behaviors" and the supportive dimension is similar to "relationship behaviors".

\subsection{Leadership Style Approach: Tasks vs. Relationships}

There are two important behaviors related to leadership style: task and relationship. Task behaviors focus on goal accomplishment (Northouse, 2007, p. 65). For example, it is important for a task-oriented leader to think about the tasks of the organization by figuring out the most efficient, effective, and productive way to complete all tasks (Kaifi, 2009, p. 92). Relationship behaviors help subordinates feel comfortable with any situation in which they find themselves (Northouse, 2007, p. 65). For example, it is important for a relationship-oriented leader to help colleagues with personal and work-related problems. Being too task-task oriented or too relationship-oriented can create unwanted quandaries. Consequently, finding the optimum way to lead has been the goal of researchers at different universities.

\subsection{The Ohio State University Studies}

In the late 1940s, the leadership research program at "Ohio State" measured specific leadership behaviors. The researchers had subordinates complete questionnaires about their leaders by using the Leader Behavior Description Questionnaire (LBDQ). Researchers found that subordinates' responses on the questionnaire clustered around two underlying dimensions of leader behaviors: initiating structure and consideration (Stogdill, 1974). Initiating structure behaviors were essentially "task" behaviors focused on getting work completed as efficiently as possible. On the other hand, consideration behaviors were essentially "relationship" behaviors focused on building friendships. Around the same time, researchers at the University of Michigan were also investigating leadership behavior.

\subsection{University of Michigan Studies}

The "Michigan studies" revealed two types of leadership behaviors: employee orientation and production orientation. Surprisingly, those studies revealed similar concepts to initiating structure and consideration. Employee orientation describes the behaviors of leaders who approach followers or subordinates with a humanistic perspective or "relationship" orientation. On the other hand, production orientation describes the behaviors of leaders who focus on productivity and efficiency or "task" orientation. Northouse (2007) explains, Unlike the Ohio State researchers, the Michigan researchers, in their initial studies, conceptualized employee and production orientations as opposite ends of a single continuum" and further explains, "that leaders who were oriented toward production were less oriented to employees, and those who were employee oriented were less production oriented (p. 68). Since then, researchers have used this framework to better understand the behaviors of leaders from different cultures (Mujtaba \& Kaifi, 2010; Tajaddini \& Mujtaba, 2009). For the purpose of this study, pharmacist leadership styles will be evaluated from a culturally diverse population.

\subsection{Contemporary Leaders}

Today's competitive organizations demand leadership. Leadership is about behavior first and skills second. Strategic leaders have a vision, are able to influence followers, and are able to transform their vision into action. It all comes back to promoting positive expectations and having those expectations realized. Hallowell (2011) explains, "Using the tool you know best - yourself - to connect with others and help others also connect, you can bring out the best in the people you lead" (p. 98). Consequently, universities need to train students to become leaders that are able to influence others to complete tasks, develop long-lasting relationships, and follow the mission of an organization.

Interestingly enough, most people don't seek to be leaders because "as you take the role of a caring leader; people soon begin relating to you differently" (Kouzes \& Posner, 2003, p. 77). A strong leader must have self-confidence and must be able to listen, consult, involve, and explain why and how things should be done. Sheetz-Runkle (2011) states that, "Boldness, decisiveness, commitment, authority, conviction, and right decision making are qualities that influence self-confidence" (p. 45). Leaders are also able to empower followers by "making key behaviors automatic" (Schwartz, Jones, \& McCarthy, 2010, p. 37). Thus, it is imperative for pharmacists to develop sound leadership skills.

\section{Methods}

\subsection{Data Collection Process}

An electronic survey using Opinio was created and a link to the survey was emailed to a all pharmacists working in Florida who are serving (or recently served) as preceptors for the NSU College of Pharmacy $(n=520)$. The list of the 
preceptors' emails was sourced from the database of clinical preceptors maintained by NSU. While there are no precise definitions of the demographics of the preceptor population available, it was expected to be diverse and include large numbers of women. Participants received a link to the electronic survey that took approximately 12 minutes to complete. As an incentive to complete the survey, participants received an automatic scoring of their personal leadership style along with interpretative materials at the end of the survey.

A personalized appeal email was sent to the population asking them to participate with a link to the survey along with informed consent. Participants who consented could access a link that took them to the survey questions. Email reminders (with a link to the survey) were sent every 10 days for a total of 3 attempts to achieve a maximal response rate. Confidentially of survey responses was maintained with no collection of names, workplace addresses, or specific age.

\subsection{Survey Instrument}

Leadership style was measured using the Style Questionnaire, a survey instrument validated in several different populations. (Northouse 2007) The Style Questionnaire contains a total of 20 questions using a 5 point Likert-type scale to assess agreement with certain behaviors. Ten questions are used to determine task orientation and ten questions are used to determine relationship orientation (See Appendix A). The reliability of the Style Questionnaire has been tested with Cronbach's alphas ranging from 0.89 to 0.95 and deemed sufficient for social science research (Anderson 2006, Madlock 2008, Mujtaba 2009). Cultural data was collected using 14 additional survey questions designed to elicit information on the background of the individual. Most of these questions were obtained from the demographics section of the 2009 National Pharmacy Workforce Survey. Two questions provided data on both actual and preferred work cultures (Tharp 2009). IRB approval was sought to conduct both a pilot and the full study. The survey instrument was then pilot tested on 40 NSU College of Pharmacy faculty members. The response rate was $80 \%(\mathrm{n}=32)$ for the pilot study. A revision to one question, ethnicity, was made based upon pilot responses. Pilot responders confused race with ethnicity so a change to the sequencing of those questions was made to clarify it.

\subsection{Scoring}

Scoring of the leadership style questions is divided into two subscales. There is one subscale each for relationship and task oriented behaviors. Task behavior is the extent to which the leader spells out the duties and responsibilities of an individual or group. It includes giving directions and setting goals. Relationship behavior is the extent to which the leader engages in two-way or multi-way communication. It includes such activities as listening, providing encouragement, and coaching. Ten questions made up each subscale with a minimum score of 10 and a maximum of 50. The predominant leadership style is determined from each of the subscale scores where a score of 40 or more $(80 \%)$ was considered high engagement in behavior and 39 or less was considered low engagement. Thus, there are 4 styles of leadership:

1) Authoritarian with high task and low relationship behavior.

2) Delegator with a low task and low relationship behavior.

3) Participators with low task and high relationship behavior.

4) Salespersons with high task and high relationship behavior.

A sensitivity analysis on each of the subscore was also conducted such that a range of the mean score of + or -1 point was used to determine a possible secondary style.

\subsection{Statistical Analysis}

Descriptive statistics were calculated including frequencies for each variable. Tests for differences in means were conducted using the two sample T-test and one-way ANOVA. Levene's test for equal variances was used to test ANOVA assumptions. Multiple regression models using the linear model of ANOVA were conducted using the dependent variable, leadership score along with significant predictor values from the one-way ANOVA models. Both a main effects and a model including interaction terms was tested. Hypotheses testing was considered significant at a p-value of 0.05 or less. Both SPSS 16 and SAS Enterprise Guide were used as the software for the analysis.

\section{Results}

\subsection{Response Rate}

Of the 520 surveys sent, 14 were returned as undeliverable. Thus, the adjusted sample size was 506 . A total of 131 responses were received yielding a response rate of $28.9 \%$.

\subsection{Individual Cultural Characteristics}

Respondents were about half female and half male. The majority were young adults (ages 21-40), white race, with 24\% of Hispanic ethnicity, born in the U.S., with a Christian religious preference, possessing a PharmD degree, and performing as managers who supervised more than 5 persons in either a community or hospital pharmacy setting. (Table 2) 
Table 2. Cultural Characteristics of Respondents

\begin{tabular}{|c|c|}
\hline Characteristics & Frequency $(\%)$ \\
\hline Age & \\
\hline $21-30$ & $10(7.7)$ \\
\hline $31-40$ & $50(38.5)$ \\
\hline $41-50$ & $34(26.2)$ \\
\hline $51-60$ & $29(22.3)$ \\
\hline Over 60 & $7(5.4)$ \\
\hline Birthplace & \\
\hline US & 98 (76.6) \\
\hline Non-US & $30(23.4)$ \\
\hline Current position & \\
\hline Owner/Partner/Executive officer & $8(4.7)$ \\
\hline Management & $87(66.9)$ \\
\hline Staff & $31(23.8)$ \\
\hline Other & $4(2.4)$ \\
\hline Ethnicity & \\
\hline Not Hispanic, Latino, or Spanish origin & $101(77.7)$ \\
\hline Hispanic, Latino, or Spanish origin & $29(22.3)$ \\
\hline Gender & \\
\hline Male & $63(48.5)$ \\
\hline Female & $67(51.5)$ \\
\hline Highest degree earned & \\
\hline Bachelor & $30(23.2)$ \\
\hline Master & $11(8.5)$ \\
\hline Doctor of Pharmacy & $86(66.6)$ \\
\hline Number of Languages Spoken in Childhood & \\
\hline 1 & $79(63.7)$ \\
\hline 2 & $38(30.6)$ \\
\hline 3 or more & $7(5.6)$ \\
\hline Language today & \\
\hline English & $116(89.9)$ \\
\hline Spanish & $13(10.1)$ \\
\hline Personnel supervised & \\
\hline None & $18(13.8)$ \\
\hline $1-4$ & $38(29.2)$ \\
\hline $5-8$ & $27(20.8)$ \\
\hline $9-12$ & $11(8.5)$ \\
\hline 13 or more & $36(27.7)$ \\
\hline Primary practice pharmacy setting & \\
\hline Clinic or doctor office & $11(8.4)$ \\
\hline Community pharmacy & $59(45.0)$ \\
\hline Hospital pharmacy & 47 (35.9) \\
\hline Other & $12(9.1)$ \\
\hline Race & \\
\hline White & $98(76.0)$ \\
\hline Non White & $31(24.0)$ \\
\hline Religion & \\
\hline Christian & $74(65.5)$ \\
\hline Non- religious & $12(10.6)$ \\
\hline Non- Christian & 27 (23.9) \\
\hline Year receiving first pharmacy license & \\
\hline Before 1981 & $21(16.9)$ \\
\hline 1981-1990 & $25(20.1)$ \\
\hline $1991-2000$ & $30(24.1)$ \\
\hline $2001-2010$ & $48(38.7)$ \\
\hline
\end{tabular}




\subsection{Perceived and Preferred Work Cultures}

Most respondents identified themselves as currently working in a collaborative (38\%) or controlling (28\%) work culture. If given their preference, the majority would like to work in a collaborative (53\%) or creative (26\%) organization. (Table 3)

Table 3. Current and Preferred Work Environment

\begin{tabular}{lll}
\hline Work Culture Type $^{\mathrm{a}}$ & Current (\%) & Prefered (\%) \\
\hline Collaborate (Clan) & $46(38)$ & $67(53)$ \\
Create (Entrepreneurial) & $16(13)$ & $33(26)$ \\
Control (Hierarchy) & $34(28)$ & $16(13)$ \\
Compete (Performance) & $25(21)$ & $10(8)$ \\
\hline
\end{tabular}

${ }^{\mathrm{a}}$ : The following descriptions for the work environment were given in the survey Collaborate

- An open and friendly place to work where people share a lot of themselves.

- Leaders are considered to be mentors or even parental figures.

- Group loyalty and sense of tradition are strong.

- There is an emphasis on the long-term benefits of human resources development and great importance is given to group cohesion.

- There is a strong concern for people.

- The organization places a premium on teamwork, participation, and consensus.

Create

- A dynamic, entrepreneurial, and creative place to work.

- Innovation and risk-taking are embraced by employees and leaders.

- A commitment to experimentation and thinking differently are what unify the organization.

- The long-term emphasis is on growth and acquiring new resources.

- Being an industry leader is important.

- Individual initiative and freedom are encouraged.

Control

- A highly structured and formal place to work.

- Rules and procedures govern behavior.

- Leaders strive to be good coordinators and organizers who are efficiency-minded.

- Maintaining a smooth-running organization is most critical.

- Formal policies are what hold the group together.

- Stability, performance, and efficient operations are the long-term goals.

Compete

- A results-driven organization focused on job completion.

- People are competitive and goal-oriented.

- Leaders are demanding, hard-driving, and productive.

- The emphasis on winning unifies the organization.

- Reputation and success are common concerns.

- Long-term focus is on competition and achievement of measurable goals and targets. 


\subsection{Leadership Style}

Responses to the STYLE questionnaire indicated that the most frequent leadership style was "selling" or high task-high relationship behavior (53\%). A low task-high relationship style "participating" style was evident in $22 \%$ of respondents. Fewer (14\%) identified themselves as having a low task-low relationship "delegating" style and only $10 \%$ had a high task-low relationship "authoritarian" style (Table 4).

Table 4. Leadership Styles of Pharmacist Preceptors ( $\mathrm{n}=125)$

\begin{tabular}{cccccc}
\hline Leadership Style & $\begin{array}{c}\text { Task } \\
\text { Relationship }\end{array}$ & Frequency & Percent & $\begin{array}{c}\text { Cumulative } \\
\text { Frequency }\end{array}$ & $\begin{array}{c}\text { Cumulative } \\
\text { Percent }\end{array}$ \\
\hline \multirow{2}{*}{ Authoritarian } & High & & & & \\
& Low & 13 & 10.40 & 13 & 10.40 \\
Low & Low & 18 & 14.40 & 31 & 24.80 \\
Participator & Low & & & & \\
& High & 28 & 22.40 & 59 & 47.20 \\
Selling & High & & & & \\
& High & 66 & 52.80 & 125 & 100.00 \\
\hline
\end{tabular}

Authoritarian-High task and Low relationship. This "telling" style is very directive because the leader produces a lot of input but a minimum amount of relationship behavior. This is the style a general would use to lead an army in battle. Authoritarian leaders are very good at guiding and directing. They can be negatively perceived as dominating, controlling and demanding. With some people this style reinforces insecurity, reduces their enthusiasm for work, creates a dependency on the leader for all decisions, and demeans the subordinate.

Selling - High task and High relationship. The "selling" style is also very directive, but in a more persuasive, guiding manner. The leader provides considerable input about task accomplishment but also emphasizes human relations. Selling leaders are good at explaining and persuading. They can be criticized by some as preaching, defending, and rationalizing their behaviour. They want to "fix" things in the group so that tasks will get done smoothly. Their need to direct tasks means that they may hinder growth and stifle initiative in some subordinates.

Participators-Low Task and High Relationship. In the "participating" leadership style, there is less direction and more collaboration between leader and group members. The consultative and consensus subtypes of participative leader generally fit into this quadrant. Participating leaders can be perceived positively as friendly and encouraging. They are problem solvers who are willing to help when needed. They tend to let employees set their priorities. Participating leaders can be negatively perceived as having inflated expectations. They can act in a pacifying manner, tend to be nonspecific, and may be patronizing by giving unearned praise. They can be accused of not letting go or under-trusting since they want to be involved in most group situations. In some situations, they appear to waver, stall, and be indecisive.

Delegators-Low Task and Low Relationship In the "delegating" leadership style, the leader delegates responsibility for a task to a group member and is simply kept informed of progress. If carried to an extreme, this style would be classified as free-rein. Delegating leaders are observant and monitor from a distance. They are perceived by some as uninterested, uncaring, and inaccessible because they don't maintain close relationships with employees. Others may feed dumped on or ignored with this type of leadership.

\subsection{Leadership Style and Cultural Attributes}

The main hypothesis of the study was that leadership style does vary by cultural attributes. Testing of this hypothesis (Table 5) indicates that mean leadership style did vary significantly by the following attributes: 
Table 5. Leadership Style by cultural attributes ( $\mathrm{t}$-test and one-way ANOVA)

\begin{tabular}{|c|c|c|c|c|c|c|c|c|}
\hline Cultural group & & Style* & $\begin{array}{l}\text { Leadership } \\
\text { score }\end{array}$ & $P$ value & Task & $\begin{array}{l}\mathbf{P} \\
\text { value }\end{array}$ & Relationship & P value \\
\hline \multirow[t]{2}{*}{ Age } & 40 or less & P-S & 80.7 & 0.017 & 39.2 & 0.012 & 41.8 & 0.115 \\
\hline & 41 or more & S & 84.3 & & 41.6 & & 42.9 & \\
\hline \multirow[t]{2}{*}{ Birth Place } & US & P-S & 81.5 & 0.007 & 39.7 & 0.006 & 41.9 & 0.023 \\
\hline & Other & S & 86.3 & & 42.8 & & 43.9 & \\
\hline \multirow{3}{*}{$\begin{array}{l}\text { Current } \\
\text { Position }\end{array}$} & Executive & S & 85.3 & 0.004 & 42.6 & 0.000 & 43.3 & 0.185 \\
\hline & Manager & S & 84.2 & & 41.6 & & 42.9 & \\
\hline & Staff & $\mathrm{P}$ & 78.6 & & 37.3 & & 41.4 & \\
\hline \multirow{4}{*}{$\begin{array}{l}\text { Current Work } \\
\text { Culture }\end{array}$} & Collaborate & $\mathrm{S}$ & 83.4 & 0.059 & 41.1 & 0.192 & 42.7 & 0.059 \\
\hline & Create & S & 86 & & 41.4 & & 44.7 & \\
\hline & Control & $\mathrm{P}$ & 79.7 & & 38.8 & & 41.3 & \\
\hline & Compete & $\mathrm{S}$ & 83.1 & & 41.1 & & 41.9 & \\
\hline \multirow[t]{3}{*}{ Ethnicity } & Not Hispanic & S-P & 82.2 & 0.537 & 40.1 & 0.156 & 42.3 & 0.798 \\
\hline & Cuban & $\mathrm{S}$ & 85.9 & & 43.8 & & 42.2 & \\
\hline & Puerto Rican & S-P & 82.5 & & 40.0 & & 42.4 & \\
\hline \multirow[t]{2}{*}{ Gender } & M & S-P & 82.8 & 0.79 & 40.6 & 0.83 & 42.7 & 0.49 \\
\hline & $\mathrm{F}$ & S-P & 82.4 & & 40.4 & & 42.2 & \\
\hline \multirow[t]{2}{*}{ Highest Degree } & Pharm.D & $\mathrm{P}-\mathrm{S}$ & 81.3 & 0.014 & 39.6 & 0.012 & 41.95 & 0.096 \\
\hline & Other degrees & $\mathrm{S}$ & 85.2 & & 42.1 & & 43.3 & \\
\hline \multirow{2}{*}{$\begin{array}{l}\text { No. Languages } \\
\text { in }\end{array}$} & 1 & $\mathrm{P}-\mathrm{S}$ & 80.8 & 0.0002 & 39.3 & 0.001 & 41.7 & 0.001 \\
\hline & 2 & S & 84.3 & & 42.0 & & 42.9 & \\
\hline Childhood & 3 or more & S & 92.8 & & 45.3 & & 47.6 & \\
\hline Language & English & S-P & 82.5 & 0.948 & 40.4 & 0.979 & 42.4 & 0.97 \\
\hline Today & Spanish & S-P & 82.7 & & 40.4 & & 42.2 & \\
\hline Personnel & 4 or less & $\mathrm{P}$ & 80.4 & 0.009 & 38.6 & 0.001 & 42.1 & 0.47 \\
\hline Supervised & 5 or more & S & 84.3 & & 41.9 & & 42.6 & \\
\hline \multirow{3}{*}{$\begin{array}{l}\text { Practice } \\
\text { Setting }\end{array}$} & Community & S-P & 82.9 & 0.955 & 40.6 & 0.867 & 42.8 & 0.847 \\
\hline & Hospital & S-P & 82.5 & & 40.7 & & 41.8 & \\
\hline & Clinic & $\mathrm{P}$ & 81.9 & & 38.6 & & 43.3 & \\
\hline \multirow{4}{*}{$\begin{array}{l}\text { Preferred } \\
\text { Work Culture }\end{array}$} & Collaborate & S-P & 82.3 & 0.392 & 40.0 & 0.548 & 42.6 & 0.182 \\
\hline & Create & S & 83.7 & & 41.2 & & 42.7 & \\
\hline & Control & S-P-D-A & 80 & & 40.3 & & 40.3 & \\
\hline & Compete & $\mathrm{S}$ & 85.4 & & 42.2 & & 43.7 & \\
\hline \multirow[t]{2}{*}{ Race } & White & S-P & 82.4 & 0.682 & 40.3 & 0.66 & 42.4 & 0.872 \\
\hline & Not White & S-P & 83.0 & & 40.9 & & 42.3 & \\
\hline \multirow[t]{2}{*}{ Religion } & Christian & S-P & 81.6 & 0.115 & 40.1 & 0.31 & 41.7 & 0.043 \\
\hline & Non Christian & S & 84.0 & & 41.0 & & 43.3 & \\
\hline Year of & Before 1981 & S & 85.4 & 0.048 & 42.3 & 0.044 & 43.7 & 0.174 \\
\hline \multirow[t]{3}{*}{ Licensure } & 1981-1990 & $\mathrm{S}$ & 83.4 & & 41.5 & & 42.1 & \\
\hline & $1991-2000$ & S-P & 84.0 & & 40.0 & & 43.1 & \\
\hline & $2001-2010$ & $\mathrm{P}$ & 80.1 & & 38.9 & & 41.5 & \\
\hline
\end{tabular}

* $\mathrm{P}=$ Participative $\mathrm{S}=$ Selling $\mathrm{D}=$ Delegating $\mathrm{A}=$ Authoritarian 
1) Age: younger persons had lower mean task and overall scores than older persons. Younger persons tend towards a participative style while older persons have a selling style of leadership.

2) Birthplace: U.S. born preceptors had lower overall, task, and relationship scores tending towards a participative style. While those born outside the U.S., had a predominantly selling style of leadership.

3) Current Position: Executives and Managers had higher task and overall scores than staff persons. Both Executives and Managers have a selling style, while staff persons were strongly participative in style.

4) Current work culture: preceptors perceiving themselves to be in a controlling type of work culture have lower task and overall scores than those in other work cultures.

5) Highest degree held: preceptors with a Doctor of Pharmacy degree had lower overall and task scores tending towards a participative style while those with other degrees were predominately using the selling style.

6) Number of languages spoken in childhood: preceptors speaking only 1 language in childhood had significantly lower scores in overall, task, and relationship scores preferring a participative style. Multilingual preceptors strongly preferred the selling style of leadership.

7) Supervisors: preceptors who supervised fewer than 4 persons had lower overall and task scores and thus were more participative than those supervising 5 or more persons were tended to have a selling style.

8) Religion: Christians had higher relationship scores than non-Christians. However, both groups have a dominant selling style.

9) Year of Licensure: preceptors licensed before 2000 have higher task and overall scores than those licensed from 2001-2010. The earlier the year of licensure the more highly the selling style of leadership was preferred.

Attributes that were not significantly related to leadership score in this study included ethnicity, gender, language spoken today, practice setting, preferred work culture, and race.

4.6 Predictors of Leadership Style

A multiple regression analysis (Table 6) of main effects was run to test the model using all the significant variables from the one-way ANOVA analyses. The model was specified as:

Table 6. Multiple regression model (ANOVA) for Leadership Score (Main Effects)

\begin{tabular}{cccccc}
\hline Source & DF & Sum of Squares & Mean Square & F ValuePr $>$ F \\
\hline Model & 17 & 2923.51 & 171.97 & 3.16 & 0.0002 \\
Error & 100 & 5447.84 & 54.47 & & \\
Corrected Total & 117 & 8371.35 & & & \\
\hline
\end{tabular}

\begin{tabular}{cccc}
\hline R-Square & Coeff Var & Root MSE & Leadership Score Mean \\
\hline 0.35 & 8.91 & 7.38 & 82.76 \\
\hline
\end{tabular}

\begin{tabular}{cccccc}
\hline Source & DF & Type III SS & Mean Square & \multicolumn{2}{c}{ F Value Pr $>$ F } \\
\hline Age & 1 & 26.37 & 26.37 & 0.48 & 0.4882 \\
Birthplace & 1 & 51.71 & 51.71 & 0.95 & 0.3323 \\
No. Languages Spoken in Childhood & 2 & 564.65 & 282.32 & 5.18 & 0.0072 \\
Year of Licensure & 3 & 387.34 & 129.11 & 2.37 & 0.0751 \\
Current Position & 3 & 451.69 & 150.56 & 2.76 & 0.0459 \\
Highest Degree & 1 & 3.25 & 3.25 & 0.06 & 0.8074 \\
Number of Supervisees & 1 & 52.28 & 52.28 & 0.96 & 0.3296 \\
Religion & 2 & 49.57 & 24.78 & 0.46 & 0.6357 \\
Current Work Culture & 3 & 105.76 & 35.25 & 0.65 & 0.5866 \\
\hline
\end{tabular}




\begin{tabular}{|c|c|c|c|c|c|}
\hline Parameter & & Estimate & Standard Error & t Value & $\operatorname{Pr}>|t|$ \\
\hline Intercept & & 93.02 & 4.771 & 19.46 & $<.0001$ \\
\hline \multirow[t]{2}{*}{ Age } & 40 or less & -1.54 & 2.22 & -0.70 & 0.4882 \\
\hline & 41 or more & 0.00 & . & . & . \\
\hline \multirow[t]{2}{*}{ Birthplace } & Non-US & 1.92 & 1.977 & 0.97 & 0.3323 \\
\hline & United States & 0.00 & . & . & . \\
\hline \multirow[t]{3}{*}{ No. Languages Spoken in Childhood } & one & -10.36 & 3.50 & -2.96 & 0.0038 \\
\hline & two & -6.88 & 3.42 & -2.01 & 0.0472 \\
\hline & three or more & 0.00 & . & . & . \\
\hline \multirow[t]{4}{*}{ Year of Licensure } & 1981-1990 & -3.52 & 2.40 & -1.47 & 0.1456 \\
\hline & $1991-2000$ & 0.76 & 2.59 & 0.29 & 0.7690 \\
\hline & $2001-2010$ & -3.64 & 3.08 & -1.18 & 0.2398 \\
\hline & Before 1981 & 0.00 & . & . & . \\
\hline \multirow[t]{4}{*}{ Current Position } & Executive & 0.21 & 3.89 & 0.06 & 0.9551 \\
\hline & Manager & 4.18 & 1.97 & 2.11 & 0.0370 \\
\hline & Other & -4.21 & 4.67 & -0.90 & 0.3701 \\
\hline & Staff & 0.00 & . & . & . \\
\hline \multirow[t]{2}{*}{ Highest Degree } & Doctor of Pharmacy & -0.48 & 1.96 & -0.24 & 0.8074 \\
\hline & $\begin{array}{c}\text { Bachelor/Other } \\
\text { degree }\end{array}$ & 0.00 & . & . & . \\
\hline \multirow[t]{2}{*}{ Number of Supervisees } & 4 or less & -1.68 & 1.71 & -0.98 & 0.3296 \\
\hline & 5 or more & 0.00 & . & . & . \\
\hline \multirow[t]{2}{*}{ Religion } & Christian & -1.27 & 1.67 & -0.76 & 0.4493 \\
\hline & Non-Christian & 0.00 & . & . & . \\
\hline \multirow[t]{4}{*}{ Current Work Culture } & Collaborate & 0.55 & 1.95 & 0.28 & 0.7770 \\
\hline & Create & 0.52 & 2.47 & 0.21 & 0.8339 \\
\hline & Control & -1.97 & 2.17 & -0.91 & 0.3654 \\
\hline & Compete & 0.00 & . & . & . \\
\hline
\end{tabular}

Leadership Score $=\beta_{0}+\beta_{1}$ Age $+\beta_{2}$ Birthplace $+\beta_{3}$ Current Position $+\beta_{4}$ Current Work Culture $+\beta_{5}$ Highest degree + $\beta_{6}$ Number of Languages Spoken in Childhood $++\beta_{7}$ Number of Supervisees $+\beta_{8}$ Religion $+\beta_{9}$ Year of Licensure. The model was significant overall, $\mathrm{F}=3.16, \mathrm{P}=0.0002, \mathrm{R}^{2}=0.35$ with two significant predictor variables: Number of languages spoken in childhood and current position as a manager. Several interaction terms were tested since age is correlated with many of the main effects. Interactions of age with a preceptor's current position, highest degree, number of supervisees, and year of licensure was tested. A check of another interaction, current position with number of supervisees was also added. A model including these interactions terms along with the main effects was run on leadership scores. Overall, this model was significant, and $\mathrm{R}^{2}$ improved to 0.37 , however, none of the interaction terms were significant, so these terms were dropped and the main effects model was deemed to be the best fitting model.

\section{Discussion}

We found that the majority of pharmacist preceptors that we surveyed have a selling style of leadership, similar to the two previous surveys of pharmacy leadership styles discussed in the introduction. However, unlike the past surveys, we did detect that a shift towards a preference for other styles, especially participative and delegating styles, is occurring. We also found that leadership style does vary considerably by cultural attributes. The model explains a 
moderate level of the leadership score variance $\left(\mathrm{R}^{2}=0.35\right)$ with the cultural attributes of multilingualism in childhood and performing in a managerial role predictive of leadership style (more indicative of a selling style).

Cultural differences in leadership style appears to be due more to a change in task orientation since relationship scores were high across all the cultural groups. Multilingual preceptors, especially those in management roles, will tend to have higher task expectations than most of the staff and students they interact with on a daily basis. A clash in these two leadership styles can create conflict, especially in situations where a subordinate may desire less direction (participative style) and a preceptor and/or manager is directive in nature (selling or authoritarian style). Another example of conflict that can arise is when a preceptor becomes disappointed in a student (participative style) who continually wants to work with a group of students collaboratively rather than independently. Or on the flip side, sometimes a student feels like they need more direction in a task and a preceptor (participative or delegating style) is less than directive because "she wants the student to learn how to do it on their own".

It is perhaps not surprising that managers will tend to be more task oriented since in the short term this leadership style is effective in many situations. It was surprising that multilingualism in childhood was just as strong of a predictor as having a management role (both had a partial R's of 9\%) since neither race nor ethnicity were associated with leadership style. It's possible that persons who become fluent in more than one language use this skill to be more persuasive (selling their ideas) regardless of environment. There are hints that other factors may have a role, such as generation. Year of licensure is a proxy for generation and two (1981-1990 and 2001-2010) seemed to be leaning towards more participative or delegating styles of leadership. A larger survey might be able to detect this difference more clearly.

The results of this study can be used by pharmacist preceptors in several ways. First, a self assessment of leadership style can be made. Knowing yourself can be helpful in dealing with others. Second, preceptors could use the instrument to have students self-assess and where both the student and preceptor are willing, they could share their tendencies. This self disclosure could help them create a more cooperative working relationship. It is important to point out that there is no wrong style of leadership. As mentioned above, in the situational leadership model, the leadership style used depends on the circumstances. For example, authoritarian style is called for in situations where the follower is either not confident or competent to proceed on their own (Hersey \& Blanchard, 1977). Furthermore, this research will help healthcare and pharmaceutical researchers, professionals, and practitioners strategically prepare and plan for "Obamacare" which refers to the Patient Protection and Affordable Care Act (PPACA).

\subsection{Limitations}

Since the measures of leadership were all based on self-reporting by pharmacists, the limitations of self-reporting should be considered in interpreting these findings. As it was a self-administered mail survey, there is the potential for non-response bias. Personalized mailings, repeated contacts and mailings were used to try to limit non-response bias. In survey research, results may be biased by social desirability effect. This means that respondents may be tempted to give a socially desirable response rather than what they think or believe. Assurance of confidentiality may have helped to reduce social desirability bias. When reviewing the results of this study, one should review with caution before assuming that this model can be generalized to all pharmacists. We surveyed only pharmacists who are practicing in a limited region (Florida) and those pharmacists who volunteer as preceptors. It is possible that pharmacists who are practicing in Florida as preceptors are different than pharmacists who practice in other states or who don't precept students.

\subsection{Summary}

This study is intended to provide a conceptual framework that enables pharmacist preceptors to use leadership styles appropriately and to increase their effectiveness in working with a variety of students. This study confirms that most pharmacists still utilize the selling style of leadership. However, it appears that other styles are becoming more dominant especially among younger, U.S. born, highly educated preceptors. Two factors can be used to predict leadership style, having a management position and multilingualism in childhood. Both of these factors point to a stronger selling style of leadership. Repeated study in a variety of pharmacist preceptor populations is needed to confirm these findings before generalizations can be made.

\section{References}

Anderson, C.M., Madlock, P.E., \& Hoffman P. (2006). Leadership, commitment, and attitudes as predictors of satisfaction in small task groups. Presented paper, Central States Communication Association Convention, Indianapolis, IN. 
Hallowell, E.M. (2011). Shine: Using brain science to get the best from your people. Harvard, MA: Harvard Business Review.

Hersey, P., \& Blanchard, K.H. (1969). Life-cycle-theory of leadership. Training and Development Journal, 23, 26-34.

Hersey, P. \& Blanchard, K. H. (1977). Management of Organizational Behavior 3rd Edition- Utilizing Human Resources. New Jersey/Prentice Hall.

Ibrahim, M.I., Wertheimer, A.I., Myers, M.J., McGhan, W.F., \& Knowlton, C.H. (1997). Leadership styles and effectiveness: Pharmacists in associations vs. pharmacists in community settings. Journal of Pharmaceutical Marketing \& Management, 12(1), 23-32. http://dx.doi.org/10.3109/J058v12n01_02

Jones, G.R. \& George, J.M. (2008). Contemporary Management. New York: McGraw-Hill.

Kaifi, B.A. (2009). $21^{\text {st }}$ century leadership in healthcare. Pages 90-100. Chapter Twelve in the Pharmaceutical Technician Laboratory Manual by Sandeep Bansal. Boston, Massachusetts: Jones and Bartlett Publications.

Kaifi, B.A. (2013). Organizational Behavior: Managing and Leading Organizations. Tamarac, FL: Llumina Press.

Kouzes, J., \& Posner, B. (2003). Encouraging the Heart. San Francisco, CA: Jossey-Bass.

Lumsden, G., Lumsden, D., \& Wiethoff, C. (2010). Communicating in Groups and Teams: Sharing leadership (5 ${ }^{\text {th }}$ ed). Boston, MA: Wadsworth Cengage.

Madlock, P.E. (2009). The link between leadership style, communicator competence, and employee satisfaction. Journal of Business Communication, 45(1):61-78. http://dx.doi.org/10.1177/0021943607309351

Mujtaba, B.G., Khanfar, N.M., Khanfar, S.M. (2010). Leadership tendencies of government employees in Oman: A study of task and relationship based on age and gender. Public Organization Review: A Global Journal, 10, $173-190$

Mujtaba, B.G., \& Kaifi, B.A. (2010). An inquiry into eastern leadership orientation of working adults in Afghanistan. Journal of Leadership Studies, 4(1), pp. 36-46. http://dx.doi.org/10.1002/jls.20153

National Pharmacist Workforce Survey-2009, Midwest Pharmacy Workforce Research Consortium, Pharmacy Manpower Project, March 1, 2010 accessed from www.aacp.org

Northouse, P. G. (2004). Leadership: Theory and Practice ( $3^{\text {rd }}$ ed.). Thousand Oaks, California: SAGE.

Northouse, P.G. (2007). Leadership: Theory and Practice (4th ed.). Thousand Oaks, CA: Sage Publications.

Parrett, E.E., Hurd, P.D., Northcraft, G., McGhan, W.F., \& Bootman, J.L. (1985). Leadership styles of hospital pharmacy directors. American Journal of Hospital Pharmacy, 42, 1069-1073.

Pohlman, R.A., Gardiner, G.S., \& Heffes, E.M. (2000). Values Driven Management. New York: American Management.

Rath, T., \& Conchie, B. (2009). Strengths Based Leadership. NY: Gallup Press.

Schwartz, T., Jones, J., \& McCarty, C. (2010). The Way We're Working Isn't Working. New York, NY: Free Press.

Stogdill, R.M. (1974). Handbook of Leadership: A Survey of Theory and Research. New York: Free Press.

Sheetz-Runkle, B. (2011). Sun Tzu for Women: The Art of War for Winning in Business. Cincinnati, OH: Adams Business.

Tajaddini, R., \& Mujtaba, B.G. (2009). Stress perceptions and leadership orientation of Malaysians: Exploring their similarities and difference with Americans. Chinese Business Review, 8(8), pp. 26-42.

Tharp, B.M. (2009). Four Organizational Culture Types. Organizational Culture White Paper, Haworth Press.

U.S. Census Bureau. (2009). Statistical Abstract of the United States. Washington, DC: U.S. Census Bureau.

Vroom, V. (1973). A new look at managerial decision making. Organizational Dynamics, 73 (1), pp. 66-80. http://dx.doi.org/10.1016/S0090-2616(73)80024-5 


\title{
APPENDIX A
}

\author{
业任 \\ NOVA Sournestrax \\ College of Pharmacy \\ 11501 N. Military Trail \\ Palm Beach Gardens, FL 33410
}

Dear Participant:

Thank you for taking part in this important research project. We are asking you to voluntarily respond to a questionnaire designed to measure leadership styles of pharmacist preceptors from different cultural backgrounds. Culture is defined to include generation, gender, work environment, race, language, etc. The survey consists of 36 questions and will take about 15 minutes of your time to complete. After you've completed the survey, we will provide you with an evaluation of your personal leadership style along with some educational material about different leadership styles based on the work by experts, Dr. Paul Hersey and Dr. Ken Blanchard. Should you experience any problems or have any questions about your survey, please contact me, Dr. Nile Khanfar, either by telephone at (954) 262-5642 or e-mail me at khanfar@nova.edu and I will assist you. Please select choices for ALL questions since incomplete surveys will limit the ability of the program to accurately determine your leadership style.

\section{THANK YOU!}

Nile M. Khanfar, Ph.D., M.B.A.

Assistant Professor

(954) 262-5642

For questions 1 to 20, think about how you usually behave when you work in a group. After reading a statement, indicate the degree to which you engage in this behavior using the 1 to 5 scale. A rating of 1 means you NEVER behave that way and a rating of 5 means you ALWAYS behave that way.

\begin{tabular}{|c|c|}
\hline & Always \\
\hline 1. Tells group members what they are supposed to do. & 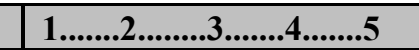 \\
\hline 2. Acts friendly with members of the group. & 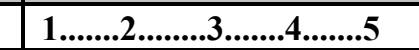 \\
\hline 3. Sets standards of performance for group members. & $1 \ldots \ldots . . . . . . . . .3 \ldots . . . .4 \ldots . . .5$ \\
\hline 4. Helps others feel comfortable in the group. & 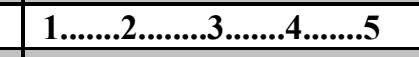 \\
\hline 5. Makes suggestions about how to solve problems. & $1 \ldots \ldots . .2 \ldots \ldots . . . .3 \ldots . . .44 \ldots . . .5$ \\
\hline 6. Responds favorably to suggestions made by others. & 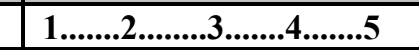 \\
\hline 7. Makes his or her perspective clear to others. & $1 \ldots \ldots . . . . . . . . .3 \ldots . . . . .4 \ldots \ldots . . .5$ \\
\hline 8. Treats others fairly. & 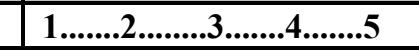 \\
\hline 9. Develops a plan of action for the group. & 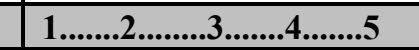 \\
\hline 10. Behaves in a predictable manner towards group members. & 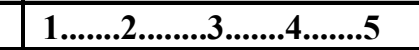 \\
\hline 11. Defines role responsibilities for each group member. & $1 \ldots \ldots . . . . . . . .3 \ldots . . . .4 \ldots . . .5$ \\
\hline 12. Communicates actively with group members. & 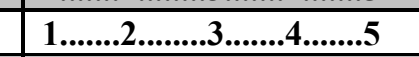 \\
\hline 13. Clarifies his or her own role within the group. & $1 \ldots \ldots . . . . . . . . .3 \ldots . . . .4 \ldots . . . .5$ \\
\hline 14. Shows concern for the well-being of others. & 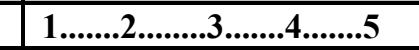 \\
\hline 15. Provides a plan for how the work is to be done. & 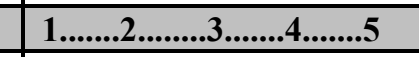 \\
\hline 16. Shows flexibility in making decisions. & 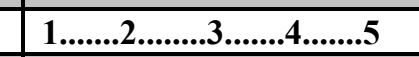 \\
\hline 17. Provides criteria for what is expected of the group. & $1 \ldots \ldots . . . . . . . . .3 \ldots . . . .4 \ldots . . .5$ \\
\hline 18. Discloses thoughts and feelings to group members. & $1 \ldots \ldots . .2 \ldots . . . . .3 \ldots \ldots . . . . . . . .55$ \\
\hline 19. Encourages group members to do high-quality work. & $1 \ldots \ldots . . .2 \ldots \ldots . . . .3 \ldots \ldots . . . . . . . .5$ \\
\hline 20. Helps group members get along. & 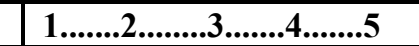 \\
\hline
\end{tabular}


21. What is your age group? (Select ONE)
a. $21-25$
b. $26-30$
c. $31-35$
d. $36-40$
e. $41-45$
f. $46-50$
g. $51-55$
h. $56-60$
i. $61-65$
j. $\quad 66-70$
k. over 70

22. What is your gender? (Select ONE)
a. Male
b. Female

23. Which of the following best describes your race? (Select ONE)
a. Asian
b. Black
c. White
d. American Indian or Alaska Native
e. Pacific Islander/Samoan/Hawaiian
f. Mixed race (also answer question 23.1)
g. Don't know
h. Prefer not to respond

23.1 If mixed race, which ONE GROUP do you most identify with? (Select ONE)
a. Asian
b. Black
c. White
d. American Indian or Alaska Native
e. Pacific Islander/Samoan/Hawaiian
f. Don't know
g. Prefer not to respond

24. Are you of Hispanic, Latino, or Spanish origin?(Select ONE)
a. No
b. Yes, Mexican/Chicano or Mexican American
c. Yes, Puerto Rican
d. Yes, Cuban
e. Yes, Other: Specify

25. Where were you born? (Select ONE)

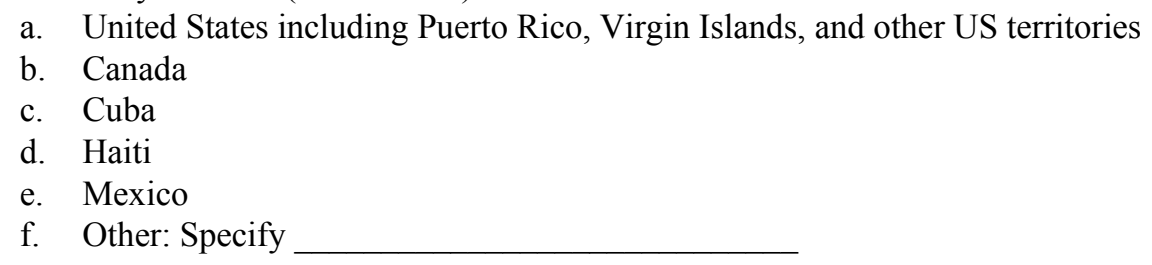


26. How many years have you lived in the United States? YEARS

27. Which language(s) did you speak while growing up? (Select ALL that apply.)
a. Creole
b. English
c. Spanish
d. Other: Specify
e. Other: Specify
f. Prefer not to respond

28. Which ONE language do you speak the most today? (Select ONE)
a. Creole
b. English
c. Spanish
d. Other: Specify
e. Prefer not to respond

29. What is your primary religious affiliation? (Select ONE)
a. Buddhist
b. Christian
c. Hindu
d. Jewish
e. Muslim
f. Other: Specify
g. Not religious
h. Prefer not to respond.

30. What year did you first receive your pharmacy license? (Select ONE)
a. Before 1965
b. $1966-1970$
c. 1971-1975
d. $1976-1980$
e. 1981-1985
f. $1986-1990$
g. 1991-1995
h. 1996-2000
i. 2001-2005
j. 2006-2010

31. What is the highest degree that you earned? (Select ONE)
a. Bachelors degree
b. Masters degree
c. Doctor of Pharmacy
d. Ph.D.
e. Other: Specify 
32. Where do you primarily practice pharmacy today? (Select ONE)
a. Clinic or Doctors Office
b. Community pharmacy
c. Hospital pharmacy
d. Mail service pharmacy
e. Nursing home pharmacy
f. Pharmacy benefit manager or insurance company
g. Other: Specify

33. How many personnel are under your supervision at primary practice site? (Select ONE)
a. None, other than myself
b. $1-4$
c. $5-8$
d. $9-12$
e. 13 or more

34. Which of the following best describes your current position? (Select ONE)
a. Owner/Partner/Executive Officer
b. Management (e.g., director, manager, assistant manager, supervisor)
c. Staff (e.g., clinical pharmacist, staff pharmacist, consultant)
d. Other: Specify

Please read the descriptions of the 4 different work cultures below to answer questions 35 and 36:

\section{Work Culture A}

- An open and friendly place to work where people share a lot of themselves.

- Leaders are considered to be mentors or even parental figures.

- Group loyalty and sense of tradition are strong.

- There is an emphasis on the long-term benefits of human resources development and great importance is given to group cohesion.

- There is a strong concern for people.

- The organization places a premium on teamwork, participation, and consensus.

\section{Work Culture B}

- A dynamic, entrepreneurial, and creative place to work.

- Innovation and risk-taking are embraced by employees and leaders.

- A commitment to experimentation and thinking differently are what unify the organization.

- The long-term emphasis is on growth and acquiring new resources.

- Being an industry leader is important.

- Individual initiative and freedom are encouraged.

\section{Work Culture C}

- A highly structured and formal place to work.

- Rules and procedures govern behavior.

- Leaders strive to be good coordinators and organizers who are efficiency-minded.

- Maintaining a smooth-running organization is most critical. 
- Formal policies are what hold the group together.

- Stability, performance, and efficient operations are the long-term goals.

\section{Work Culture D}

- A results-driven organization focused on job completion.

- People are competitive and goal-oriented.

- Leaders are demanding, hard-driving, and productive.

- The emphasis on winning unifies the organization.

- Reputation and success are common concerns.

- Long-term focus is on competition and achievement of measurable goals and targets.

35. Select the ONE work culture that BEST describes your current work environment:
a. Work Culture A
b. Work Culture B
c. Work Culture C
d. Work Culture D

36. Of the work cultures described above, which ONE culture would you PREFER to work within?
a. Work Culture A
b. Work Culture B
c. Work Culture C
d. Work Culture D 